Journal of Research in Interprofessional

Practice and

Education

Vol. 8.1

2018

\title{
Nursing and Biomedical Laboratory Science (BMLS) Students' Interprofessional Training in the Simulation Laboratory
}

\author{
Frøydis Vasset, PhD, Lindis Helberget, MD, \\ \& Synnøve Hofseth Almås, PhD, Norwegian University \\ of Science and Technology (NTNU)
}

\begin{abstract}
Background: The purpose of this study is to present nursing and Biomedical Laboratory Science (BLMS) students' perceptions of interprofessional education and collaborative practice in a simulation laboratory.

Method: A mixed-method research was employed, and the approach was an explanatory sequential design. A quantitative study was followed by a qualitative study. Sixty-nine students participated in the survey, with 16 items representing different aspects of interprofessionalism.

Findings: The factor "value of IPE" scored the highest mean, followed by the factor "need for collaborative practice." Female students were more positive on the "value of IPE" than male students. The focus-group interviews revealed that the students considered debriefing afer the simulation to be a useful learning opportunity. They commented that it was useful to understand each other's roles and it made them respect each other more. BMLS students felt that they were peripheral to the case, like a visitor in the simulation scenario.

Conclusion: Information for this study was gathered from a large group in a short amount of time. However, the students gained an insight into the need for an interprofessional approach to complex challenges in healthcare.

Keywords: Simulation; IPE; Nursing student; Biomedical laboratory science student; Mixed-method
\end{abstract}

\section{Introduction}

Interprofessional education

A Norwegian White Paper [1] indicates a strong growth in the need for different health services and collaborative practice. Collaborative practice must be learned,

Journal of Research in Interprofessional Practice and Education (JRIPE)

Vol. 8.1

(C) 2018

doi: 10.22230/ijepl.2018 v8n1a271

Corresponding author: Frøydis Vasset. Email: fv@ntnu.no but interprofessional education (IPE) has not always found a proper place in education and placements [1]. Interprofessional education (IPE) describes those occasions when two or more professionals learn with, from, and about each other to improve collaboration and the quality of care [2].

The importance of interprofessional working in the health education program has been underlined in several White Papers in recent years [3-5]. The Framework for Action on Interprofessional Education and Collaborative Practice [6] urged health education institutions to train students to become comfortable with future interprofessional interactions. The World Health Organization (WHO) [6] also reported that being interprofessional is a way of thinking and working that practitioners learn and 
2

Interprofessional Training in the Simulation Laboratory

Vasset, Helberget, \& Almås

Journal of Research in Interprofessional Practice and Education

Vol. 8.1

2018 refine over time. A study [7] explored reflection as a learning tool and referral as a key aspect of working with other professionals or students. Learning is an active process; it happens when we engage with problems, challenges, new ideas, or unfamiliar practices and acquire new knowledge through this commitment. To acquire interprofessional competence, IPE must be practiced and taught during the study period [8].

In the health domain, IPE is a response to the realities of fragmented healthcare practices [9]. It is a foundation for collaborative, patient-centred practice systems [10]. As mentioned in a White Paper [5], IPE should be implemented in all health and social education. However, there is no indication as to when or how IPE should be carried out. There are many methods for IPE, including lecture-based, writingbased, action-based, exchange-based, observation-based, simulation-based, and practice-based laboratory activities [11]. There are also many barriers to effective IPE, including logistical problems and overcoming traditional professional boundaries [12], and perhaps some gender differences.

\section{Case simulation in the exercise laboratory}

Simulation has been implemented as a pedagogical method in the curriculum for bachelor's degrees in several educational institutions. Simulation is especially suitable for training communication and interaction in acute situations. To equip nursing students for practice studies, there has been a tradition of practical training in procedures at training departments. To improve this, simulation laboratories have set up one or more simulator machines, such as SimMan and SimPad [13].

Simulation imitates a real situation in which a model of the environment, available resources, and people are involved. Using a simulator doll can enhance technical skills and foster more complex interpersonal relationships [14]. Simulations challenge students' learning, both cognitively through problem-solving and critical thinking and psychomotor and technical skills, and affectively in terms of using nontechnical skills such as communication, collaboration, and management [15].

A facilitator leads the planning and implementation of the simulation. This person leads or guides the different parts of the simulation. This may involve defining learning outcomes, introducing the activity, setting rules for participating, and leading the debriefing [16].

The purpose of the present study was to examine nursing students' and biomedical laboratory science (BMLS) students' experiences of interprofessional working in the simulation laboratory and their perceptions of interprofessionalism.

\section{Research about simulation-based training and patient safety}

At least 44,000 people, and perhaps as many as 98,000 people, die in hospitals each year in the United States alone due to medical errors or a failure of collaboration that could be prevented [17]. A recent report suggests that similar factors undermine patient safety in Europe [18]. Collaborative practice is necessary, especially in emergency care in hospital settings. Ensuring effective working between professionals presupposes an understanding of the others' practical and theoretical starting points: their vocational understanding [19]. Simulation is an attractive method for 
3

Interprofessional Training in the Simulation Laboratory

Vasset, Helberget, \& Almås

Journal of Research in Interprofessional Practice and Education

Vol. 8.1

2018
IPE [20]. One of the challenges for interprofessional simulation training is to demonstrate that the training really benefits patients [21].

Simulation-based training is one of the most important measures to improve patient safety and reduce the number of adverse events in hospital departments [18, 22]. In a study, students expressed the view that making mistakes was uncomfortable, despite the fact that this was just a simulation situation [23]. This was especially related to an occurrence in a scenario in another study where a patient needed a blood transfusion. Here, the informants reported that during the simulation, several teams had given the wrong blood because the patient's identity was not managed properly [24]. Yet another study [25] found that the use of a virtual patient in IPE activity facilitated the achievement of interprofessional learning objectives, including the development of greater awareness of other professionals and the ways in which collaborative patient care can be provided. Research [26] also found that educational activity involving a virtual patient improved a variety of healthcare students' interprofessional competence. In summary, the evidence to date indicates that IPE improves students' attitudes to teamwork skills and leads to better professional practice and patient care.

\section{Reflection as a pedagogical method in simulation laboratory}

Students construct their own learning within social frameworks. According to David Kolb's theory, learning is a process in which knowledge is formed through the transformation of experience in four stages [27]. First, students experience a given situation. Next, students reflect on their experiences and what they mean. Based on reflective observation, students structure and generalize or formalize the learning outcomes of their experiences. Later this knowledge will be tested in new contexts.

One particular study [28] shows that scenario-based simulation experiences in themselves are no guarantee of learning; they need to be part of a systematic process that incorporates reflection on the action. Without reflection, simulation experiences result in limited learning [29]. The literature connected to IPE also underlines that reflection is a key ingredient in effective teamwork, pedagogical method, and practice [30-32]. Several other studies show that debriefing with an emphasis on reflection helps ensure learning in the simulation situation [20,33]. A study [34] found that simulation is an effective pedagogical method to achieve learning objectives in the curriculum. Another study [23] found that students in such a situation would reveal their attitudes and their ability to speak out to each other.

In the IPE field, collaborative and experiential learning-such as a group of students from different backgrounds working together on a clinical case-is the cornerstone of many methods of learning how to work in a team [33]. In this context, learning is a process or a cycle, not a product or an outcome. The knowledge and skills acquired by the participants are the learning itself [11].

In IPE, students must use a methodology that serves all aspects of collaboration in a patient's healthcare, involving both clinical care and organizational collaboration $[35,36]$. Research underlines that there is a growing need for faculty training in the use of simulation-based IPE tools and techniques [37]. It also indicates that simulation is better than other educational techniques, leading to its spread [38]. Some 
4

Interprofessional Training in the Simulation Laboratory

Vasset, Helberget, \& Almås

Journal of Research in Interprofessional Practice and Education

Vol. 8.1

2018 attractive features of simulation are a close resemblance to actual clinical practice, more feedback, and the ability to assess psychomotor performance.

The objective of this study was to explore male and female nursing and BMLS students' positive and negative experiences of using simulation as a pedagogical method for IPE.

\section{Method}

Students (both nursing and BMLS) collaborated in a simulation laboratory involving a "child" who needed a blood transfusion. There were ten students in each simulation team. Two BMLS students and three nursing students acted in each simulation intervention, and three nursing students and two BMLS students had observer status. In total 70 students participated. At the end of each simulation intervention, the students had a debriefing with a facilitator. In all, the team took one hour to complete this pedagogical intervention. For BMLS students, the learning outcomes were transfusion medicine, collecting a venous blood sample from a child and the ordering of and preparation for blood sampling. For nursing students, this was part of a week of child nursing that the students have each year. Both professions emphasize communication with patients and relatives as well as interprofessional collaboration. In the debriefing situations, the nursing teachers conducted a reflective discussion with the entire group. Debriefing has three stages: 1) the description phase, 2) the analysis phase, and 3) the application phase [13].

The Norwegian Social Science Data Services (NSD) approved this study. All participants were given verbal information about the purpose of the project. The participants in focus-group interviews were informed that the data would be audio taped, transcribed, and then anonymized. All data were deleted after the study was completed.

\section{Design}

A mixed-method explanatory sequential design was used in this study. Mixedmethod research involves collecting both quantitative and qualitative data $[39,40]$. Design theory [39] emphasizes that a great deal of published research incorporates mixed methods in the social and human sciences in diverse fields, such as interprofessional communication. The time dimension in mixed methods is either sequential or parallel. The sequential form means that one type of data provides a basis for the collection of another type of data, while in parallel form data collection is concurrent. This study collected, analyzed, and integrated quantitative data (a survey) with subsequent qualitative data (focus-group interviews) in a sequential manner.

\section{Survey}

\section{Participants}

The sample consisted of 70 students (50 nursing students and 20 BMLS students). All students were in their final semester of a three-year degree program. In total 69 students filled out the questionnaire, representing 99 percent of the total undergraduate healthcare student population. 
JRIPE

5

Interprofessional

Training in the

Simulation

Laboratory

Vasset, Helberget, \& Almås

\section{Instrument}

For the quantitative data, the students answered a survey after the simulation intervention. One part of the questionnaire included references to biosocial variables such as professional program, gender, age, and experiences in healthcare. The other part of the questionnaire concerned perceptions of interprofessionalism and built on earlier research [41]. The questionnaire has been subject to several revisions since it was first developed with 50 items in 1996. For our purposes, 16 items asserting different

\section{Table 1. Rotated factor loading for 16 items using Principal Component Analysis}

\begin{tabular}{|l|c|c|c|c|}
\hline & \multicolumn{3}{|c|}{ Factors } \\
\cline { 2 - 5 } & 1 & 2 & 3 & 4 \\
\hline $\begin{array}{l}\text { 1. Normally it is an advantage that a group consists of members from different } \\
\text { professions for comprehensiveness in teamwork. }\end{array}$ & 0.74 & 0.08 & 0.20 & 0.35 \\
\hline $\begin{array}{l}\text { 2. When care is given by a group consisting of different health professions, the } \\
\text { quality is better than care from an individual professional. }\end{array}$ & 0.71 & 0.24 & 0.04 & 0.07 \\
\hline 3. Groups made up of different health professions give a better holistic view. & 0.69 & 0.10 & 0.46 & 0.30 \\
\hline $\begin{array}{l}\text { 4. If different professions work in a group, the patient will have more efficient } \\
\text { treatment. }\end{array}$ & 0.66 & 0.32 & 0.27 & 0.11 \\
\hline $\begin{array}{l}\text { 5. When different professions work in a group, the patient will have more } \\
\text { information about available health services. }\end{array}$ & 0.63 & 0.08 & 0.05 & 0.13 \\
\hline $\begin{array}{l}\text { 6. Groups made up of different health professions are more efficient at offering } \\
\text { good treatment. }\end{array}$ & 0.59 & 0.10 & 0.27 & 0.39 \\
\hline 7. Interprofessional learning leads to a holistic insight in health service. & 0.11 & 0.80 & 0.04 & 0.11 \\
\hline $\begin{array}{l}\text { 8. Knowledge about other health professions would make me a better health } \\
\text { worker. }\end{array}$ & 0.26 & 0.67 & 0.42 & 0.27 \\
\hline $\begin{array}{l}\text { 9. I will be better qualified as a health worker if interprofessional learning is } \\
\text { included in my education. }\end{array}$ & 0.43 & 0.66 & 0.01 & 0.01 \\
\hline 10. I find it interesting to have insight into other health professions. & 0.28 & 0.60 & 0.46 & 0.01 \\
\hline $\begin{array}{l}\text { 11. I do not see the purpose of doing projects with students from other } \\
\text { professions. }\end{array}$ & 0.08 & 0.01 & 0.79 & 0.06 \\
\hline 12. I do not see the value of teamwork across professional boundaries. & 0.36 & 0.23 & 0.71 & 0.23 \\
\hline 13. I want to have more information about other health professions. & 0.05 & 0.38 & 0.47 & 0.40 \\
\hline $\begin{array}{l}\text { 14. Interprofessional learning is not necessary for understanding other related } \\
\text { professions. }\end{array}$ & 0.11 & 0.03 & 0.12 & 0.71 \\
\hline 15. Interprofessional learning gives better knowledge about other professions. & 0.15 & 0.18 & 0.00 & 0.71 \\
\hline $\begin{array}{l}\text { 16. I feel that I would acquire knowledge about the roles in other professions } \\
\text { through interprofessional learning }\end{array}$ & 0.05 & 0.52 & 0.00 & 0.53 \\
\hline Mean & 4.00 & 4.00 & 3.33 & 3.67 \\
\hline Cronbach's a & 0.84 & 0.79 & 0.57 & 0.53 \\
\hline Eigenvalue & 6.1 & 1.5 & 1.3 & 1.2 \\
\hline \% of variance & 37 & 9 & 8 & 7 \\
\hline
\end{tabular}

Journal of Research in Interprofessional Practice and Education

Vol. 8.1

2018 
6

Interprofessional Training in the Simulation Laboratory

Vasset, Helberget, \& Almås

Journal of Research in Interprofessional Practice and Education aspects of interprofessional education and collaborative practice were identified through statistical procedures (see Table 1). In order to avoid bias resulting from interprofessionalism often being characterized as having a positive impact, a definition of the concept was omitted from the instructions given with the questionnaire. The items were formulated as statements and rated using a 6-point Likert scale, ranging from "strongly disagree" (1) to "strongly agree" (6). The survey was forwarded by email, without incentives, to the students directly after the simulation intervention.

\section{Data analysis}

The quantitative data from the students were analyzed using the statistical package SPSS version 24. To reduce the items, factor analysis was conducted. Data were subjected to principal component factor analysis (PCA) with varimax rotation to explore underlying factors. To find out if the data were suitable for principal component factor analysis, Kaiser-Meyer-Olkin (KMO) and Bartlett's tests of significance were performed. Using KMO, values ought to be higher than 0.6 [42]. In this material, KMO was 0.81. In addition, a Bartlett's Test was significant at the $p=0.000$ level. Both criteria showed that the data were suited to a factor analysis design. The reliability of the factors that emerged was investigated using Cronbach's alpha. Oneway ANOVA and $t$-tests were conducted to find differences between the professional groups' gender and experience in healthcare.

\section{Findings}

Principal component factor analysis (PCA) of the 16 items resulted in five factors, each with an Eigen value greater than one. One of the factors contained fewer than three items. One theorist [43] argues that three or more items should load on each component to increase Cronbach's alpha. The number of factors was therefore reduced to four. As Table 1 shows, Cronbach's alphas [42] for the four factors were $0.84,0.79,0.57$, and 0.53 . (With short scales, it is common to find quite low values of Cronbach's alpha $[42,43]$.)

Six items had factor loadings greater than 0.5 on the first factor (accounting for $37 \%$ of the variance) (see Table 1). Based on the contents of items with high loadings, the first factor seemed to involve the construct "Need for collaborative practice." Items in the first factor highlighted that efficiency and quality in healthcare is associated with collaborative practice. The second factor was composed of four items with factor loading above 0.6 (accounting for $9 \%$ of the variance). This factor seemed to involve a construct of the "Value of IPE." The scree test was applied to determine the number of reliable factors. Based on the plot of the eigenvalues and the result of Cronbach's alpha, two factors seem to be appropriate. According to Table 2, the factor "Value of IPE" scores the highest mean, followed by the factor "Need for CP." There is no statistically significant difference between the two
Table 2. Mean and standard deviation for the factors

\begin{tabular}{|l|c|c|c|}
\hline Factor & Mean & $\begin{array}{c}\text { Standard } \\
\text { deviation }\end{array}$ & Number \\
\hline Value of IPE & 5.59 & 0.49 & 69 \\
\hline Need for CP & 5.42 & 0.55 & 69 \\
\hline
\end{tabular}


7

Interprofessional Training in the Simulation Laboratory

Vasset, Helberget, \& Almås
Journal of Research in Interprofessional Practice and Education factors and study direction in secondary school, or whether the students had experience in healthcare. Gender showed a statistically significant difference for the factor "Value of IPE" ( $p=0.02)$. Female students were more positive on the "Value of IPE" (mean $=5.61)$, while male students were somewhat less positive $($ mean $=5.30)$.

\section{Focus-group interviews}

\section{Participants}

Two focus-group interviews were conducted. Three BMLS students participated in one interview, and three nursing students participated in the other. All the students were offered an opportunity to participate in the interviews, but only six students volunteered. Focus-group interviews are characterized by the interaction between the interviewees [44]. The interviews were tape recorded (with informants' permission) and transcribed verbatim. All data was anonymized. The following interview guide was used in the focus group interviews:

1. How did you experience IPE in the simulation laboratory?

2. How did you experience the group size in IPE?

3. How did you experience working in interprofessional groups?

4. How do you think that IPE can effect a patient's overall care?

5. Tell us about the debriefing after the simulation situation.

\section{Data analysis}

The qualitative data were analysed using Giorgi's recommendation for content analysis by condensing the statements to meaningful statements and categorizing them. The texts were analyzed in four steps: 1) to get an overall impression, 2) to identify meaningful devices, 3) to abstract the content of meaningful devices, such as categories, and 4) to summarize the meanings for the theme [45].

\section{Findings from the interviews}

The data was analysed in three main categories: 1) IPE in the simulation laboratory, 2) the informants' advice on how IPE in the simulation laboratory could be improved, and 3) unfortunate components in the IPE intervention. Each main category had three subcategories. Direct quotes from informants are presented in italics.

\section{IPE in the simulation laboratory}

- Learning of, with, and about other professions

Students in BMLS reported that they learned more about how nursing students in the simulations organized themselves, and vice versa.

- Learning outcomes of the simulation

A BMLS student said that she did not think that nursing students in the simulation intervention learned much about the BMLS job. On the other hand, a nursing student reported that he/she thinks it was a useful and instructive simulation situation. I would love to have more such great simulations. I had hoped that there was more of it when I started the program. 
Interprofessional Training in the Simulation Laboratory

Vasset, Helberget, \& Almås
Journal of Research in Interprofessional Practice and Education

- Learning about reflection and debriefing after the simulation One of the nursing students thought it was easier to talk in small groups than in the lessons where there were huge groups of students (approximately 130 students). The student thought that debriefing after the simulation was good for learning: I suppose that when we have simulated and had debriefing afterwards, we think and reflect on what we have done, what we actually learned.

The informants' advice on how IPE in the simulation laboratory could be improved

- Timing for IPE

The students stated that it would be useful to have simulation training earlier in the bachelor's degree because they could practice and then collaborate in their placements and experience each other's roles in the health profession.

- Knowledge about other professional roles

One of the students reported that: In order improve collaboration in patient care, students must also understand other professionals' work and roles in the relief work. One of the BMLS students commented: If we collaborate with each other, then we also respect each other and understand each other more.

- Other implementation models for IPE in the simulation laboratory?

Students wanted IPE and simulation earlier in their study. They wanted fewer students in the simulation group (not 10 students as in this study), and cases that are more related to BMLS. They want real technical solutions at the simulation work: Not just simulating a phone in a phone call.

Unsatisfactory components in the IPE intervention

- Simulating IPE

A BMLS student was confused by the fact that the work was not carried out as it might usually be performed in a hospital. The student said: I do not fully know the purpose of this. It is to learn about a nurse's job or treatment of a patient. If it was the latter, it did not meet the purpose.

- Disrupted communication in IPE

One nursing student thought the scenario was quite chaotic with IPC too many students in the laboratory. This was considered a barrier to communication between the two groups of students.

- Lack of collaborations

Several of the students experienced some difficulty in collaborating. The BMLS students felt they were treated as guests and they did not feel completely integrated in the team. The students also reported that they had little time to complete the work and they had to hurry during the simulation. 
9

Interprofessional Training in the Simulation Laboratory

Vasset, Helberget, \& Almås

Journal of Research in Interprofessional Practice and Education Vol. 8.1 2018

\section{Discussion}

The purpose of this study was to examine the IPE experience of nursing and BMLS students in the simulation laboratory and their perceptions of collaborative practice and interprofessional education.

\section{Improving the IPE simulation}

Nursing students reported that it was useful for them to use the simulator as a tool for training, to collaborate with each other and other student professionals, and to take care of the patient. They indicated that they would like to have more simulation-based learning. Some of the BMLS students expressed that they were not included in the whole simulation intervention, and this intervention was not, therefore, successful for them. This resulted from the organization and preparation of the sessions, different experiences of simulation, time use, and intervention. Simulation is considered one of the most practice-oriented methods to learn interprofessional competencies and these findings correspond with other research in the field $[18,22,34,37,38]$ that underlines simulation-based training as one of the most important measures to improve patient safety $[23,25,26]$.

When students from several different professions understand and respect each other and their different kinds of work, they also gain the opportunity to improve patient safety [23]. Failures in communication within interprofessional healthcare teams are established causes of medical error and negative health outcomes [46]. This study shows that it is important to improve communication, and it is helpful for both the nursing and the BMLS students to collaborate more to achieve the best care for the patient.

\section{Challenges with interaction in the simulation laboratory}

Some of the students experienced little collaboration between the professions in the simulation intervention. The students assumed that they had to hurry through the scenario, and the nursing students found the scenario quite chaotic with too many students involved. While the nurses tried to focus on the patient's health and suffering, they forgot to collaborate with BMLS students. The lack of collaboration and unfortunate lack of communication between students can often lead to uncertainty in vulnerable patient groups [47], such as children.

The BMLS students used different terms to convey information or express differences in the patient's diagnosis [45]. This may signal that nursing and BMLS students should simulate more together so that they learn and respect each other's contributions. This was also mentioned in one of the focus-group interviews. The third and last year of the bachelor's degree may be too late to start with simulation training and IPE. Participating in simulation as a pedagogical tool was a new experience for BMLS students, and some of them were a bit confused. The nursing students had used the simulation laboratory from the first year in their study, but mostly in clinical procedures and with other students in their own profession. 
10

Interprofessional Training in the Simulation Laboratory

Vasset, Helberget, \& Almås

Journal of Research in Interprofessional Practice and Education

\section{Reflecting and learning from the debriefing situation}

The students indicated that it was generally easier for them to discuss and reflect on the situation when they worked in small groups. During the debriefing, the students reflected on the simulated activity and what the collaborative practice meant for patient care [27]. This applies both in the simulation situation and in the debriefing afterward. This can thus lead to useful learning. Several research studies underlined the advantage of this reflection process [28-32]. Some research [20,33] attaches particular importance to debriefing after a simulation session. Reflection after a simulation session is one of the most important activities in the simulation work. A facilitator should encourage reflection and not be negative about an unsatisfactory performance during the simulation. The group members should go from the simulation laboratory with a feeling of a job well done and not a feeling of failure [16].

\section{Perceptions of interprofessionalism}

In general, all the students in this study seemed to see the need for interprofessional education and collaboration. Research emphasizes that health services place little emphasis on collaborative practice, which has led to IPE being more important in basic education [11]. Unsatisfactory communication between different professionals has led to the unnecessary suffering of patients [48]. The students in this study, however, were somewhat negative about IPE at the time of the simulation. This was mainly because it was at the expense of other professional learning in the last semester. Students were rather negative about having IPE in the third year of study.

\section{Male and female students' satisfaction with} the simulation and IPE

The quantitative data show that there may be some gender differences in the value of IPE. Female students were more positive toward IPE than male students. It is not clear why there were gender differences, but there are more female students in nursing education. In BMLS education, there were roughly equal numbers of males and females. The BMLS students were the ones who were the most confused in this simulation session. There may be a connection between this frustration and gender differences. Other research [49] reported similar findings in their survey study. Female students were found to have a more positive attitude toward interprofessionalism than male students. The small sample in the focus group places limitations on conclusions that can be drawn from the qualitative strand of the study.

\section{Conclusion}

The informants who participated in this simulator-based interprofessional learning reported that they gained some knowledge of each other's responsibilities and that this was part of their interprofessional collaborative skills. The organization of the project was somewhat unfortunate, with large groups and little time. The next run of the simulation-based IPE may be better organized, and lead to better IPE. The respondents emphasized that they had gained an insight into the need for an interprofessional approach to complex challenges, such as blood transfusions in a chil- 
11

Interprofessional Training in the Simulation

Laboratory

Vasset, Helberget, \& Almås

Journal of Research in Interprofessional Practice and Education

Vol. 8.1

2018 dren's ward, but the main challenge in the project was to organize the simulations for all students. The students also found that they did not have many concurrent tasks in the hospital setting. Female students were more positive to IPE than male students. Further research is needed on this gender difference.

\section{References}

1. Ministry of Health and Care Services. (2008-2009). Meld. St. Nr.47. Samhandlingsreformen: Rett behandling - på rett sted - til rett tid [Coordination reform: Proper treatment - at the right place and right time. Oslo, NO: Helse- og Omsorgsdepartementet (Regjeringen Stoltenberg II).

2. CAIPE. (2018). Centre for the Advancement of Interprofessional Education. URL: www.caipe.org.uk/ [March 3, 2018].

3. Ministry of Health and Care Services (2012-2013). Meld. St. Nr. 10. God kvalitet - trygge tjenester - Kvalitet og pasientsikkerhet i helse-og omsorgstjenesten [Good quality - safe services - Quality and patient safety in the health and care services]. Oslo, NO: Helse- og Omsorgsdepartementet (Regjeringen Stoltenberg II).

4. Ministry of Health and Care Services (2014-2015). Meld. St. Nr.11. Kvalitet og pasientsikkerhet. (Quality and patient safety). Oslo, NO: Helse- og Omsorgsdepartementet (Regjeringen Solberg).

5. Ministry of Health and Care Services (2011-2012). Meld. St. Nr. 13. Utdanning for velferd. (Education for welfare). Oslo, NO: Kunnskapsdepartementet (Regjeringen Stoltenberg II).

6. WHO. (2010). Key components of a well-functioning health system. World Health Organization. URL: http://www.who.int/healthsystems/publications/hss_key/en [March 3, 2018].

7. Hammick, M., Freeth, D., Copperman, J., \& Goodman, D. (2009). Being interprofessional. London, UK: Polity.

8. University and Higher Education Law/Council. (2016). Lov om universitet og høgskole. Endret 2016. Oslo, NO: Kunnskapsdepartementet.

9. D Àmour, D., \& Oandasan, I. (2005). Interprofessionality as the field of interprofessional practice and interprofessional education: An emerging concept. Journal of Interprofessional Care, 19(1), 8-20.

10. Kvärnstrom, S. (2008). Difficulties in collaboration: A critical incident study of interprofessional healthcare teamwork. Journal of Interprofessional Care, 22(2), 191-203.

11. Barr, H. (1994). NVQs and their implications for inter-professional collaboration. In A. Leathard (Ed.), Going inter-professional (90-108).London, UK: Routledge.

12. Vasset, F., Bergum, I.E., Inderhaug, H., \& Almås, S.H. (2014). Tverrprofesjonell e-læring som pedagogisk verktøy i helse- og sosialfagutdanninger [Interprofessional e-learning as an educational tool in health and social education]. Vård i Norden, 34(1), 19-23. URL: http://journals .sagepub.com/doi/pdf/10.1177/010740831403400106 [August 8, 2018].

13. Ødegården, T., Struknes, S., \& Hofmann, B. (2015). Pasientsimulering - en praktisk innføring [Patient simulation - A practical introduction]. Oslo, NO: Gyldendal.

14. Riva, G. (2008). From virtual to real body: Virtual reality as embodied technology. Journal of Cyber Therapy and Rehabilitation, 1(1), 7-23.

15. Issenberg, S., McGaghie, W.C., Petrusa, E.R., Lee Gordon, D., \& Jeffries, P.S. (2005). Features and uses of high-fidelity medical simulations that lead to effective learning. A BEME systematic review. Medical Teacher, 27(1), 10-28.

16. Jeffries, P.R. (2012). Simulation in nursing education. From conceptualization to evaluation. New York, NY: National League for Nursing.

17. Kohn, L., Corrigan, J., \& Donaldson, M. (2000). To err is human. National Academies of Sciences, Engineering, and Medicine Report. Building a Safer Health System. Washington, DC: National Academic Press.

18. Lockeman, K.S., Appelbaum, N.P., Dow, A.W., Orr, S., Huff, T.A., Hogan, C.J., \& Queen, B.A. (2017). The effect of an interprofessional simulation-based education program on perceptions and stereotypes of nursing and medical students: A quasi-experimental study. Nurse Education Today, 58, 32-37.

19. Willert, S., Keller, H.D., \& Stegeager, N. (2011). Academic vocational training: Bridging the gap between educational space and work. Electronic Journal of Knowledge Management, 9(2), 168-180.

20. Page, J.T., Garbee, D.D., Kozmenko, V., Quingzhao, Y., Kozmenko, L., Tong,Y., Bonanno, L., \& Swartz, W. (2014). Getting a head start: High fidelity, simulation-based operating room team training \& interprofessional students. Education, 218(1), 140-149.

21. Gosai, J., Purva, M., \& Gunn, J. (2015). Simulation in cardiology. State of the art. European Heart Journal, 36(13), 777-783. 
12

Interprofessional Training in the Simulation

Laboratory

Vasset, Helberget, \& Almås

Journal of Research in Interprofessional Practice and Education

Vol. 8.1

2018
22. McGaghie, W.C., Issenberg, S.B., Petrusa, E.R., \& Scalese, R.J. (2010). A critical review of simulation-based medical education research: 2003-2009. Medical Education, 44(1), 50-63.

23. Aase, I. (2016). Interprofessional teamwork training for nursing and medical students in Norway [PhD thesis]. Stavanger, NO: University of Stavanger.

24. Breivik, M., Johnsgaard, T., \& Hegg Reime, M. (2016). Simulering er ikke til å spøke med: Helsefagstudenters erfaringer fra tverrprofesjonell teamtrening med bruk av simuleringsmetodikk [Simulation is not to bother with: Health Sciences students experience from cross-professional team training using simulation methodology]. Nordisk Tidsskrift for Helseforskning, 12 (2), 1-18. URL: https://www.ub.uit.no/2xseptentrio/index.php/helseforsk/article/view/4054 [August 8, 2018].

25. Shoemaker, M.J., Plato, C.M., Cleghorn, S.M., \& Booth, A. (2014a). Virtual patient care: An interprofessional education approach for physician assistant, physical therapy and occupational therapy students. Journal of Interprofessional Care, 28(4), 365-367.

26. Shoemaker, M.J., Voest, M., Booth, A., Meny, L., \& Victor, J. (2015). A virtual patient educational activity to improve interprofessional competencies: A randomized trial. Journal of Interprofessional Care, 29(4), 395-397.

27. Kolb, D.A. (1984). Experiential learning: Experience as the source of learning and development. Englewood Cliffs, NJ: Prentice Hall.

28. Haaland, G., \& Nilsen, S. (2008). Loring gjennom praksis: innhold og arbeidsmåter $i$ yrkesopploringen en grunnbok i yrkesdidaktikk [Learning through practice: content and working methods in vocational education and training a basic book in professional didactics]. Oslo, NO: Pedlex norsk skoleinformasjon.

29. Sautter, M., \& Eikeland, H. (2008). The Circle of Learning in emergency medicine and healthcare education. Laerdal. URL: http://www.laerdal.com/binaries/aaoyqczs.pdf [June 9, 2018].

30. Clark, P.G. (2009). Reflecting on reflection in interprofessional education: Implications for theory and practice. Journal of Interprofessional Care, 23(3), 213-223.

31. Nilsen, S.R., Røysing, H., \& Brynhildsen, S. (2012). Erfare, skrive, dele, diskutere og lære [Experience, write, share, discuss and learn]. Uniped, 35(2), 54-66.

32. 32. Ødegaard, A., \& Willumsen, E. (2013). Reflection i interprofessionalt samarbete. In R. Axelson \& S. Axelson (Eds). Om samverkan-for utvecling av halsa och valfard [About collaboration for development of health and welfare], (pp. 179-190) Lund, NO: Studentlitteratur.

33. New, S., Huff, D.C., Hutchison, L.C., Bilbruck, T.J., \& Ragsdale, P.S. (2015). Integrating collaborative interprofessional simulation into pre-licenture health care programs. Nursing Education Perspectives: New York, 36(6), 396-397.

34. Beeman, L. (2008). Integration of simulation with existing clinical educational programs. In R. Kyle \& W. Murray (Eds). Clinical simulation - operations, engineering and management (pp. 109126). Boston, MA: Elsevier Inc.

35. Jackson, M. (2013). The Oxford handbook of the history of medicine. New York, NY: Oxford University Press.

36. Orvik, A. (2015). Organisatorisk kompetanse [Organizational competence]. Oslo, NO: Cappelen Damm Akademisk.

37. Willhaus, J. (2012). Working toward interprofessional education with simulation. Nursing Education Perspectives, 33(2), 134.

38. Palaganas, J., Epps, C., \& Raemer, D. (2014). A history of simulation-enhances interprofessional education. Journal of Interprofessional Care, (28), 1-6.

39. Creswell, J. (2014). Research design. London, UK: Sage Publications.

40. Cameron, R. (2009). A sequential mixed model research design: Design, analytical and display issues. International Journal of Multiple Research Approaches, 3(2), 140-152.

41. Almås, S.H. (2017). Interprofessional education: An analysis of the Introduction of a common core in Curricula for selected Health Professions [PhD thesis]. Bergen, NO: University of Bergen.

42. Pallant, J. (2013). SPSS survival manual. England, UK: The Mc-Graw-Hill Companies.

43. Cronback, L.J. (1951). Coefficient alpha and the internal structure of tests. Psychometrika, 16(3), 297-336.

44. Malterud, K. (2017). Kvalitative metoder i medisinsk forskning [Qualitative methods in medical research]. Oslo, NO: Universitetsforlaget.

45. Giorgi, A. (1985). Sketch of a psychological phenomenological method. Phenomenology and Psychological Research: Essays. Pittsburg, PA: Duquesne University Press.

46. Brock, D., Abu-Rish, E., Chiu, CR., Hammer, D., Wilson, S., Vorvick, L., Blondon, K., Schaad, D., Liner, D., \& Zierler, B. (2013). Interprofessional education in team communication: Working together to improve patient safety. BMJ Quality \& Safety, (22), 414-423. 
13

Interprofessional Training in the Simulation Laboratory

Vasset, Helberget, \& Almås
47. Bleakley, A., \& Bligh, J. (2008). Students learning from patients: Let's get real in medical education. Advances in Health Sciences Education, (13), 89-107.

48. Mackay, L., Soothill, K., \& Webb, C. (1995). Troubled times, the context for interprofessional collaboration. In K. Soothill, L. Mackay \& C. Webb (Eds.), Interprofessional relations in health care (pp. 5-10). London, UK: Edward Arnold

49. Curran, V.R., Shape, D., Forristall, J., \& Flynn, K. (2008). Attitudes of health sciences students towards interprofessional teamwork and education. Learning in Health and Social Care, 7(3), $146-156$. 